\title{
Epidemiological trends in community acquired acute Kidney Injury in Pakistan: 25 years Experience from a Tertiary Care Renal Unit
}

\author{
Rubina Naqvi
}

\begin{abstract}
Background: Epidemiological studies of community acquired acute kidney injury (AKI) are sparse especially from South Asia and none has published from Pakistan. Reported incidences from different countries vary with use of different criteria of defining AKI. There is also variation found in different class of income countries, hospital based versus community based AKI.

Methods: The current study was carried out in all adult AKI patients developing community acquired AKI and coming to a tertiary care renal institution from January 1990 to December 2014. This is a retrospective data collection from patient's records and AKI was defined according to KDIGO guidelines. Trends among different groups which are classified in medical, obstetrical and surgical were observed and presented.

Results: In medical AKI there has been found a rise in toxic rhabdomyolysis, vivax malaria and dengue infection during later part of study. In obstetrical AKI observed continuous rise in numbers contributing to total AKI during these years. Surgical AKI included obstructed cases during initial ten years and only surgical trauma during later 15 years. Older age on presentation in medical AKI, and thrombocytopenia, deranged coagulation, deranged liver function, hyperkalemia, requirement of mechanical ventilation and multi organ failure in all groups remained predictors of higher mortality.

Conclusion: From Pakistan epidemiology for community acquired AKI has never been published on a large scale and this study would remain source of great information in this regard over coming years.
\end{abstract}

KEYWORDS: Acute Kidney Injury (AKI), Epidemiology, Community acquired, Medical AKI, Obstetrical AKI.

How to cite this:

doi: https://doi.org/10.12669/pjms.37.2.3876

Naqvi R. Epidemiological trends in community acquired acute Kidney Injury in Pakistan: 25 years Experience from a Tertiary Care Renal Unit. Pak J Med Sci. 2021;37(2):312-319. doi: https://doi.org/10.12669/pjms.37.2.3876

This is an Open Access article distributed under the terms of the Creative Commons Attribution License (http://creativecommons.org/licenses/by/3.0), which permits unrestricted use, distribution, and reproduction in any medium, provided the original work is properly cited.

\section{INTRODUCTION}

1. Prof. Rubina Naqvi, MBBS; MD (Nephrology), FISN, PGD Bioethics. Department of Nephrology,

Sindh Institute of Urology and Transplantation (SIUT),

Civil Hospital,

Karachi, Pakistan.

Correspondence:

Dr. Rubina Naqvi

Sindh Institute of Urology and Transplantation (SIUT), Civil Hospital,

Karachi 74200, Pakistan.

Email: rubinanaqvi@gmail.com naqvirubina@yahoo.com

* Received for Publication:

November 4, 2020

* Shortened Version Received

* Edited and Corrected:

* Final Revision Accepted:
November 6, 2020

December 12. 2020

December 25, 2020
Acute kidney injury (AKI) is universally acknowledged to be a common, serious and under-recognized condition. It can occur in a variety of clinical settings, and is a predictor of adverse outcomes in the short and long-term. It is estimated that approximately 13.3 million people develop AKI around the world, of which 1.7 million die, mostly in Lower Income (LIC) and Lower Middle Income countries (LMIC). ${ }^{1}$

AKI which is one of most prominent subject in nephrology, its incidence and prevalence varies widely world over. The main reason for such wide variation remained widely used definitions for AKI which include an abrupt and sustained decline in 
renal function, a temporary rise in creatinine to at least $300 \mu \mathrm{mol} / \mathrm{L}$, an increase in serum creatinine of $>0.5 \mathrm{mg}$ per deciliter over the baseline to an increase of $>50 \%$ over the baseline value, to addition of RIFLE criteria in May 2002 in a meeting in Vicenza, AKIN classification in a meeting in Amsterdam in September 2005 and later KDIGO guidelines laid out in 2012 for definition of AKI. ${ }^{2}$

Over time, it has become clear that in high income countries, AKI develops primarily in already hospitalized patients, often with multiple preexisting conditions. However, the AKI population in low and middle income countries is generally persons who were previously healthy. A complex interplay between geographical characteristics, environmental factors, and poverty drives the presentation and outcome of this condition. ${ }^{3,4}$ AKI has a huge impact on families, societies and national economies. Knowledge of the diversity of AKI is relevant to developing a global response to mitigate the impact of this health condition, especially in resource-poor settings.

Pakistan, with a population of 215 million is a low-middle income country (nominal per capita GDP US $\$ 1,357$ in 2019) and has relatively poor health development indicators. According to the United Nations Human Development Report, Pakistan ranks 142 out of 177 countries. ${ }^{5}$ The population growth rate in Pakistan has been reported $1.92 \%$ and Health expenditure is $0.919 \%$ of GDP. ${ }^{6}$

Knowledge of epidemiology is essential to reduce preventable mortality due to AKI, as articulated by the ISN's 0by 25 program. In a country like Pakistan where almost two-thirds of the population resides in rural areas, ${ }^{7}$ many people with AKI cannot reach renal units, making it practically impossible to derive a community-based estimate of the incidence or prevalence of this condition.

The present study describes the evolution of the pattern of community-acquired AKI over a 25year period as seen at a large tertiary care hospital in Pakistan.

\section{METHODS}

This is a retrospective cohort study carried out on the basis of chart review of all patients with diagnosis of AKI admitted from January 1990 to December 2014, to the Sindh Institute of Urology and Transplantation (SIUT) Pakistan. SIUT located in city of Karachi and currently has satellite center within city and other cities; is semi-government tertiary renal care hospital funded partially by government and mainly by philanthropists; SIUT provides all facilities to patients free of cost. Since care is frequently life long, the setup provides the opportunity of gathering large amounts of data and long term follow up.

In 1990 SIUT had approximately 36 beds; by 2014 this number had increased to 450 . With its model of free care to all patients, SIUT draws patients from all over the country (travel distance may extend to 1,550 $\mathrm{Km}$ ) and sometimes from neighboring countries lacking medical facilities like Afghanistan. Patients with AKI are admitted and provided appropriate care including dialysis until death, (renal transplant from related donors in case they developed end stage renal failure) or recovery trends in renal function. Patients are discharged once it is assumed that they do not require regular dialysis and are asked to follow up in the outpatient clinics. Since many patients belong to poor socio-economic backgrounds and come from far-flung locations, follow up remains incomplete in many patients unless they experience compelling symptoms that forces them to seek medical care again.

AKI in this study was defined according to KDIGO guidelines: ${ }^{2}$ increase in serum creatinine concentration or decline in urine output were used to classify patients as having AKI. Although these patients were treated before the KDIGO criteria, it was applied retrospectively to a group of patients while going through history and presentation in records. Patients with past co-morbidities which can impact GFR like diabetes mellitus and long standing hypertension were excluded from the study.

We reviewed the records and extracted information on patients' demographic characteristics, cause of AKI, treatment provided and outcomes. The parameters recorded from day of hospital admission are given in Table-I along with serological tests were done in selected cases, use of parenteral fluids before renal replacement therapy, renal replacement therapy, sessions of hemodialysis or days on peritoneal dialysis, renal biopsy and outcome.

The outcomes were divided into death, complete recovery, when patients were followed up till gaining normal kidney functions; partial recovery, when patients were off dialysis but were lost to follow up within a 90-day period, and as having developed chronic kidney disease (CKD) when the eGFR was documented to be $<60 \mathrm{ml} / \mathrm{min} / 1.73 \mathrm{~m} 2$ beyond 90 days and end stage renal failure (ESRF) when never became dialysis free. 
The studied population has been divided over four time periods - the first being from January 1990 to December 1999, followed by three five year periods. The study protocol was in accordance with the Declaration of Helsinki and SIUT's Institutional Ethical Review Committee has granted permission for publishing this data.

Statistical Analysis: Statistical analysis was done on SPSS version 20.0. Continuous variables were expressed as mean \pm standard deviation or median with inter-quartile range. Frequencies and percentages were computed for categorical variables. Independent " $\mathrm{t}$ " test was used to determine the mean difference between outcomes while Chi- square independent or Fisher's Exact test were used to determine the proportions difference between outcomes with different presenting symptoms and multivariate logistic regression was done to identify the independent risk factors. P value $<0.05$ was considered as significant.

\section{RESULTS}

A total of 5,623 patients were diagnosed to have AKI during the study period of 1990-2014. The demographic characteristics of the population are shown in Table-I. The average age of the population was $37.74 \pm 14.89$ (range 18-100) years, and a total of 2,851 were male and 2,772 were female (M:F 1.02:1). Excluding those with AKI due to obstetric causes, males constituted $68 \%$ of the population.

A breakup of the medical causes of AKI is shown in Table-II. The most striking change was the emergence of poisoning due to Paraphenylene diamine (PPD) causing toxic rhabdomyolysis, and infection due to dengue in the later time periods. Rare causes or patients with biopsy findings of acute tubular necrosis with no supporting history are included in the miscellaneous group, while in 239 cases causes for AKI still remained unknown as they could not be biopsied.

The different causes alone or in combination in obstetrical or pregnancy related AKI are listed in Table-III. There have been continuous rising trends in pregnancy related AKI: during the initial 10 years of our data, pregnancy related AKI was $21.64 \%$ of the total. In the last 5 years, this figure jumped to $35.27 \%$.

The overall mortality was $11-33 \%$ among different groups. Regarding the outcome of AKI, 53.35 percent showed a total recovery while a partial recovery was noted in 22.81 percent. Of those who died, 14.65 percent died during the acute phase of illness and 9.19 percent developed
Table-I: Demographics of all patients.

\begin{tabular}{|c|c|c|c|}
\hline Parameters & Mean $\pm S D$ & Median & Inter quartile range \\
\hline \multicolumn{4}{|l|}{ Age (years) } \\
\hline Medical & $35.91 \pm 15.81$ & 32 & $22-45$ \\
\hline Obstetrical & $27.83 \pm 5.66$ & 27 & $24-31$ \\
\hline Surgical & $43.24 \pm 16.746$ & 42 & $30-55$ \\
\hline \multicolumn{4}{|c|}{ Duration of Insult (days) } \\
\hline Medical & $10.32 \pm 7.02$ & 8 & $6-14$ \\
\hline Obstetrical & $8.92 \pm 6.44$ & 7 & $4-12$ \\
\hline Surgical & $9.62 \pm 6.48$ & 7 & $5-13$ \\
\hline \multicolumn{4}{|c|}{ Hemoglobin $(G / d L)$} \\
\hline Medical & $10.52 \pm 3.16$ & 11 & $8-13$ \\
\hline Obstetrical & $8.14 \pm 2.06$ & 8 & $7-10$ \\
\hline Surgical & $10.51 \pm 2.67$ & 10.7 & $8.7-12.5$ \\
\hline \multicolumn{4}{|c|}{ WCC $x 10^{3} / \mu l$} \\
\hline Medical & $14.99 \pm 10.65$ & 13 & $9-18$ \\
\hline Obstetrical & $18.99 \pm 9.53$ & 17 & $12-23$ \\
\hline Surgical & $16.53 \pm 9.54$ & 13.9 & $10-21$ \\
\hline \multicolumn{4}{|c|}{ Platelet $x 10^{3} / \mu l$} \\
\hline Medical & $221.18 \pm 155.50$ & 200 & $110-299$ \\
\hline Obstetrical & $221.11 \pm 173.30$ & 169 & $97-306$ \\
\hline Surgical & $238.07 \pm 146.34$ & 210 & $135-315$ \\
\hline \multicolumn{4}{|l|}{ Urea $m g / d l$} \\
\hline Medical & $262.05 \pm 116.42$ & 245 & $178-324$ \\
\hline Obstetrical & $213.38 \pm 99.39$ & 197 & $139-265$ \\
\hline Surgical & $251.97 \pm 107.39$ & 233 & $168-313$ \\
\hline \multicolumn{4}{|c|}{ Creatinine $m g / d l$} \\
\hline Medical & $10.45 \pm 5.35$ & 9 & $7-13$ \\
\hline Obstetrical & $9.79 \pm 4.62$ & 9 & 7-12 \\
\hline Surgical & $9.36 \pm 4.48$ & 8.41 & $6.3-11.49$ \\
\hline \multicolumn{4}{|c|}{ Sodium $m E q / L$} \\
\hline Medical & $131.89 \pm 8.82$ & 132 & $127-137$ \\
\hline Obstetrical & $134.07 \pm 8.82$ & 135 & $129-139$ \\
\hline Surgical & $131.77 \pm 9.73$ & 132 & $126-138$ \\
\hline \multicolumn{4}{|c|}{ Potassium mEq/L } \\
\hline Medical & $4.54 \pm 1.38$ & 4 & $4-5$ \\
\hline Obstetrical & $4.96 \pm 1.24$ & 5 & $4-6$ \\
\hline Surgical & $4.61 \pm 1.30$ & 4.6 & $3.6-5.5$ \\
\hline \multicolumn{4}{|c|}{ Bicarb $m E q / L$} \\
\hline Medical & $14.27 \pm 5.40$ & 14 & $11-18$ \\
\hline Obstetrical & $14.67 \pm 4.89$ & 14 & $11-18$ \\
\hline Surgical & $15.51 \pm 4.82$ & 15 & $12-18$ \\
\hline \multicolumn{4}{|l|}{ AST U/L } \\
\hline Medical & $284.58 \pm 905.67$ & 56 & 30-136 \\
\hline Obstetrical & $200.41 \pm 512.21$ & 50 & $25-139.25$ \\
\hline \multirow{2}{*}{\multicolumn{4}{|c|}{$A L T U / L$}} \\
\hline & & & \\
\hline Medical & $152.70 \pm 424.32$ & 40 & $23-84$ \\
\hline Obstetrical & $163.31 \pm 505.96$ & 39 & 19-109 \\
\hline Surgical & $200.80 \pm 685.06$ & 41 & $25-96$ \\
\hline \multicolumn{4}{|c|}{ Alk Phos U/L } \\
\hline Medical & $137.86 \pm 119.41$ & 103 & $72-161$ \\
\hline Obstetrical & $165.34 \pm 135.61$ & 128 & $94-187$ \\
\hline Surgical & $167.97 \pm 158.30$ & 122 & $93-187.25$ \\
\hline \multicolumn{4}{|l|}{$L D H U / L$} \\
\hline Medical & $1677.95 \pm 2523.34$ & 973 & $447-1815$ \\
\hline Obstetrical & $1735.21 \pm 1499.89$ & 1338 & $675-2220$ \\
\hline Surgical & $1864.91 \pm 1803.77$ & 1337.50 & $622.75-2304.00$ \\
\hline \multicolumn{4}{|l|}{$C P K^{*} U / L$} \\
\hline Medical & $30777.59 \pm 129994.081$ & 1521 & $324-9388$ \\
\hline Obstetrical & - & - & - \\
\hline Surgical & $3670.82 \pm 5858.32$ & 1532.50 & $319.75-4274.00$ \\
\hline
\end{tabular}

*done in selected cases. 
Rubina Naqvi et al.

Table-II: Medical Causes of AKI.

\begin{tabular}{lccccc}
\hline Causes & $\begin{array}{c}\text { Group I } \\
(1990-1999)\end{array}$ & $\begin{array}{c}\text { Group II } \\
(2000-2004)\end{array}$ & $\begin{array}{c}\text { Group III } \\
(2005-2009)\end{array}$ & $\begin{array}{c}\text { Group IV } \\
(2010-2014)\end{array}$ & $\begin{array}{c}\text { Total 25 years } \\
(n=3,389)\end{array}$ \\
\hline Acute GE & 302 & 190 & 183 & 178 & 853 \\
Malaria & 124 & 93 & 203 & 251 & 671 \\
Rhabdomyolysis & 67 & 35 & 52 & 180 & 334 \\
GN/ Vasculitis & 88 & 32 & 36 & 80 & 236 \\
Sepsis & 71 & 31 & 28 & 32 & 162 \\
Nephrotoxic Drugs & 74 & 24 & 24 & 33 & 155 \\
Snake Bite & 38 & 16 & 30 & 31 & 115 \\
Poisons & 13 & 8 & 11 & 15 & 47 \\
HUS & 18 & 8 & 6 & 13 & 45 \\
Dengue & 0 & 2 & 9 & 32 & 43 \\
Hepato Renal Syndrome & 11 & 3 & 6 & 16 & 36 \\
Multiple Myeloma & 12 & 5 & 5 & 10 & 32 \\
Cardio Renal Syndrome & 10 & 4 & 5 & 15 & 34 \\
Acute Pancreatitis & 6 & 3 & 4 & 6 & 19 \\
Scorpion Sting & 1 & 2 & 4 & 11 & 18 \\
Misc. Causes & 86 & 70 & 90 & 104 & 350 \\
Unknown Causes & 42 & 53 & 55 & 89 & 239 \\
\hline
\end{tabular}

ESRF. Significantly higher morality was seen in patients presenting with the following issues: thrombocytopenia, hyperkalemia, deranged liver function, coagulopathy, and need for mechanical ventilatory support or multi-organ failure (MOF). Altered Glasgow Coma Scale (GCS) and older age were significantly associated with mortality in the medical group but not in others (Table-V).

Statistically, the highest mortality in the medical group was seen in patients with acute pancreatitis, cardio renal syndrome, hepato renal syndrome, hemolytic uremic syndrome, malaria and poisons.

Table-III: Obstetric Causes of AKI.

\begin{tabular}{llllll}
\hline \multirow{2}{*}{ Causes } & $\begin{array}{l}\text { Group I (1990- } \\
\text { 1999) } N=357\end{array}$ & $\begin{array}{l}\text { Group II (2000 - } \\
\text { 2004) } N=163\end{array}$ & $\begin{array}{l}\text { Group III (2005- } \\
\text { 2009) } N=286\end{array}$ & $\begin{array}{l}\text { Group IV }(2010- \\
\text { 2014) } N=635\end{array}$ & $\begin{array}{l}\text { Total 25 years } \\
\text { N=1441 }\end{array}$ \\
\hline Abortion & $49(13.7)$ & $22(13.49)$ & $35(12.2)$ & $39(6.1)$ & 145 \\
Ante Partum Haemorhage* $^{*}$ & 113 & 50 & 83 & 180 & 426 \\
Eclampsia/PET* $_{\text {Intra Uterine Death* }}$ & 66 & 17 & 37 & 107 & 227 \\
Post Partum Haemorhage* $^{*}$ & 145 & 76 & 70 & 291 & 582 \\
Sepsis* & 117 & 63 & 57 & 167 & 404 \\
HUS/HELLP & 60 & 21 & 51 & 69 & 201 \\
\hline
\end{tabular}

*more than one cause contributing to insult in many women.

Table-IV: Surgical Causes of AKI.

\begin{tabular}{lccccc}
\hline Causes & $\begin{array}{c}\text { Group I (1990 } \\
\text {-1999) }\end{array}$ & $\begin{array}{c}\text { Group II (2000 - } \\
\text { 2004) }\end{array}$ & $\begin{array}{c}\text { Group III (2005 - } \\
\text { 2009) }\end{array}$ & $\begin{array}{c}\text { Group IV (2010 - } \\
\text { 2014) }\end{array}$ & $\begin{array}{c}\text { Total 25 years } \\
(n=793)\end{array}$ \\
\hline Surgical Trauma & 135 & 48 & 74 & 87 & 344 \\
Obstructed & 449 & Not recorded & Not recorded & Not recorded & \\
\hline
\end{tabular}


Table-V: Predictors of mortality among different groups of AKI.

\begin{tabular}{|c|c|c|}
\hline Factors & Groups & P value \\
\hline Age & $\begin{array}{l}\text { Medical } \\
\text { Obstetrical } \\
\text { Surgical }\end{array}$ & $\begin{array}{c}<0.001 \\
\text { NS } \\
\text { NS }\end{array}$ \\
\hline Gender & $\begin{array}{l}\text { Medical } \\
\text { Surgical }\end{array}$ & $\begin{array}{l}\text { NS } \\
\text { NS }\end{array}$ \\
\hline Thrombocytopenia & $\begin{array}{l}\text { Medical } \\
\text { Obstetrical } \\
\text { Surgical }\end{array}$ & $\begin{array}{l}<0.001 \\
<0.001 \\
<0.001\end{array}$ \\
\hline Thrombocytosis & $\begin{array}{l}\text { Medical } \\
\text { Obstetrical } \\
\text { Surgical }\end{array}$ & $\begin{array}{l}\text { NS } \\
\text { NS } \\
\text { NS }\end{array}$ \\
\hline Hyponatremia & $\begin{array}{l}\text { Medical } \\
\text { Obstetrical } \\
\text { Surgical }\end{array}$ & $\begin{array}{l}\text { NS } \\
\text { NS } \\
\text { NS }\end{array}$ \\
\hline Hyperkalemia & $\begin{array}{l}\text { Medical } \\
\text { Obstetrical } \\
\text { Surgical }\end{array}$ & $\begin{array}{l}<0.001 \\
<0.001 \\
<0.001\end{array}$ \\
\hline Acidosis & $\begin{array}{l}\text { Medical } \\
\text { Obstetrical } \\
\text { Surgical }\end{array}$ & $\begin{array}{l}\text { NS } \\
\text { NS } \\
\text { NS }\end{array}$ \\
\hline Deranged liver function & $\begin{array}{l}\text { Medical } \\
\text { Obstetrical } \\
\text { Surgical }\end{array}$ & $\begin{array}{l}<0.001 \\
<0.001 \\
<0.001\end{array}$ \\
\hline Deranged coagulation & $\begin{array}{l}\text { Medical } \\
\text { Obstetrical } \\
\text { Surgical }\end{array}$ & $\begin{array}{l}<0.001 \\
<0.001 \\
<0.001\end{array}$ \\
\hline Hypotension & $\begin{array}{l}\text { Medical } \\
\text { Obstetrical } \\
\text { Surgical }\end{array}$ & $\begin{array}{l}\text { NS } \\
\text { NS } \\
\text { NS }\end{array}$ \\
\hline Abnormal GCS & $\begin{array}{l}\text { Medical } \\
\text { Obstetrical } \\
\text { Surgical }\end{array}$ & $\begin{array}{c}<0.001 \\
\text { NS } \\
\text { NS }\end{array}$ \\
\hline $\begin{array}{l}\text { Requirement of mechanical } \\
\text { ventilation }\end{array}$ & $\begin{array}{l}\text { Medical } \\
\text { Obstetrical } \\
\text { Surgical }\end{array}$ & $\begin{array}{c}<0.001 \\
<0.001 \\
0.002\end{array}$ \\
\hline MOF & $\begin{array}{l}\text { Medical } \\
\text { Obstetrical } \\
\text { Surgical }\end{array}$ & $\begin{array}{c}\text { NS } \\
0.002 \\
0.002\end{array}$ \\
\hline $\begin{array}{l}\text { Combination of hypotension } \\
\text { and MV }\end{array}$ & $\begin{array}{l}\text { Medical } \\
\text { Obstetrical } \\
\text { Surgical }\end{array}$ & $\begin{array}{c}<0.001 \\
<0.001 \\
\text { NS }\end{array}$ \\
\hline $\begin{array}{l}\text { Combination of hypotension, } \\
\text { MV and MOF }\end{array}$ & $\begin{array}{l}\text { Medical } \\
\text { Obstetrical } \\
\text { Surgical }\end{array}$ & $\begin{array}{l}<0.001 \\
<0.001 \\
<0.001\end{array}$ \\
\hline $\begin{array}{l}\text { Combination of abnormal } \\
\text { GCS, hypotension and MV }\end{array}$ & $\begin{array}{l}\text { Medical } \\
\text { Obstetrical } \\
\text { Surgical }\end{array}$ & $\begin{array}{c}0.004 \\
0.002 \\
<0.001\end{array}$ \\
\hline
\end{tabular}

$\mathrm{MV}=$ Mechanical Ventilation, $\mathrm{MOF}=$ Multi Organ Failure, GCS= Glasgow Coma Scale.
In the surgical group, firearm injuries, road traffic accidents, multiple bone fractures and acute abdomen resulting from visceral perforation were significant causes resulting in death of patients in the acute phase ( $p$ value $<0.05$ ).

The overall requirement for renal replacement therapy was 82 percent, indicating the severity of kidney injury on arrival. Hemodialysis was the most common modality (\%). Intermittent peritoneal dialysis was performed in 70 cases during 1990-99. CRRT was not done in any of the patients in this population. Diversion procedures like percutaneous nephrostomies or Double J stenting in bilateral obstructed kidney in Group-I patients were done.

\section{DISCUSSION}

The epidemiology of AKI has been poorly described and scarcely reported from lower income and middle lower income countries. Community acquired AKI (CA-AKI) studies are few, especially from our part of the world. A multicenter epidemiological study looking from South-East Asia that looked at AKI in intensive care units (ICUs) reported occurrence of AKI in $52.9 \%$ of ICU patients. This was based on data collected from initial 28 days of ICU admission. ${ }^{8}$ A study published from Nepal which addresses all renal disorders in outpatients or those hospitalized under nephrology care, reports AKI in $2 \%$ of out patients and in $14 \%$ of hospitalized patients. ${ }^{9}$

A study from Bangladesh found 105 cases of CA-AKI over a period of four years. The study reported different causes of AKI but did not provide the number of total admissions to this hospital during this period. ${ }^{10}$ From Pakistan, a recent study that looked at ICU patients over six months revealed AKI in $68.5 \%$ of ICU patients. ${ }^{11}$ Variations in prevalence can also occur among critically ill, sepsis association, major surgeries or among trauma patients.

Etiologies of AKI also vary in accordance with geographic and socio-economic status. Differences can be found even within studies published from the same country. For example, a study published from Northern Pakistan reports AKI in $16-20 \%$ of hospital admission and $7-10 \%$ of these were due to obstetrical causes, ${ }^{12}$ whereas a study published from a large tertiary care center in the South of the country reports 57.44 $\%$ medical and $22.87 \%$ obstetrical cases of AKI. ${ }^{13}$ Similarly, a study published from the North of India reports incidence of AKI to be $0.64 \%$ 
of hospital admissions, out of which $29 \%$ were related to use of nephrotoxic agents, followed by decreased renal perfusion $21 \%$, major surgery $18 \%$ and sepsis $17 \% .^{14}$ A study from Eastern India reports medical causes contributing $68.3 \%$, surgical $17.9 \%$ and obstetrical $13.9 \%$ to the incidence of AKI. ${ }^{15}$

The main focus of current study will remain on CA-AKI as this is a population based study carried out at a tertiary care renal unit in a LMIC, and discussion will mainly be diverted towards variation among likewise countries in this particular group of AKI.

CA-AKI from HICs has mainly been reported with rhabdomyolysis from infections, seizures, binge (prolonged lying) and disasters like earthquake or accidental trauma causing crush syndrome. Other causes include vascular events (like renal vein thrombosis) or drugs like NSAIDs. ${ }^{16}$ In the Tropics, CA-AKI has been reported from tropical infections like malaria, leptospirosis, dengue, scrub typhus, yellow fever, plants, herbicides, snake bite, scorpion stings and diarrheal illness. ${ }^{17}$ From Latin America, during 1957-1966, the most frequent causes of AKI were non compatible blood transfusion and surgery, whereas from 1980-1982, use of nephrotoxic agents was more common while in 1993, sepsis, congestive heart failure and hypotension were reported more frequently. Later, infections like leptospirosis and dengue and snake bite induced AKI and multiple bee stings have also seen from this region. ${ }^{18}$ In the present study non compatible blood transfusions and multiple bee stings are included in the miscellaneous group as their number were small thus outcomes could not be separately evaluated.

From South Africa, commonly reported causes include nephrotoxicity with use of herbal remedies in 1978, sepsis between 1986-1988, and HIV associated nephropathy in 2005-2006. From Sudan, infections like malaria and typhoid, PPD poisoning, snake bites, obstruction from urinary calculi and acute GN with descending frequency are reported. Morocco has reported sepsis, leptospirosis, toxic rhabdomyolysis followed by acute GN and obstruction as causes of AKI. ${ }^{19}$ In the current study, toxic rhabdomyolysis secondary to PPD ingestion was observed during the later period (Group IV). Dengue infection also emerged in the later part of the study, whereas malaria, GN and diarrhoeal illness showed little variation over different time periods (Table-II).
A study published from Bangladesh in past reported medical causes $78.33 \%$, surgical $18.33 \%$ and obstetrical in $10.83 \%$ of CA-AKI and they have shown overall survival rate of $75 \% .^{20}$ Another more recent study from the same country reveals still lower contribution of obstetrical AKI 4\% to the total CA-AKI. Here medical causes were contributing $86 \%{ }^{10}$

This institution, SIUT, has previously published studies that show malaria, dengue infections, rhabdomyolysis, snake bite, scorpion sting, and obstetrical reasons as causes for AKI. ${ }^{21-26}$

Among tropical infections other than malaria and dengue, leptospirosis and scrub typhus has also been reported contributing to $\mathrm{CA}-\mathrm{AKI}^{27}$ but somehow we did not find these two in our series, leptospirosis was suspected in some cases and serological tests done but only one result revealed very minimally raised titer for leptospirosis with the rest clearly negative. Other studies from the country were searched and a published study from veterinary surgeons reported leptospirosis in 40.83 $\%$ of people handling infected animals but this study did not highlight renal injury in these people..$^{28}$ Studies from Nepal and Bangladesh ${ }^{9,10}$ have also not reported this infection in their AKI experience, but Indian studies have highlighted cases reported from leptospirosis. ${ }^{17}$ Similarly, we were unable to find any scrub typhus causing AKI in the present series but we had a few enteric fever cases which were included in the miscellaneous group.

Trends of obstetrical AKI in our studies remain on the rise, ${ }^{24}$ while our neighboring country India has shown declining trends in obstetrical AKI. ${ }^{29}$ One possible reason for this decline could be the legalization of abortion, resulting in a decrease in septic abortions and related complications. Another possibility for decline in complicated obstetrics in India is launching a program which offers cash rewards to women who gave birth to their children in healthcare facilities. ${ }^{30}$ After this provision, there has been a substantial increase in the number of women delivering in institutions. In present study in the obstetrical category many women had more than one insult contributing to the cause for AKI, for example, abruptio placentae with concealed or revealed hemorrhage can cause intrauterine fetal death (IUD) and may require emergency lower segment caesarean section (LSCS) and poor handling at peripheral center may add sepsis to all this. IUD in combination of pre eclampsia (PET) can be explained on basis of widespread vascular endothelial cell dysfunction resulting in 
vasospasm, inadequate placental circulation. ${ }^{31}$ Some studies have reported IUD as independent risk factor for maternal disease. ${ }^{32}$ Similarly LSCS alone has also been reported to cause maternal morbidity and contribute to AKI. ${ }^{33}$ Among all three categories in our study, we had the highest number of partially recovered patients in the obstetrical group which may highlight the socio cultural setup of the country and gender biases that result in male members of the family seeking treatment while women's health is ignored. Another issue is that many of the women suffering from AKI were left at their parents' homes by their husbands. If their fathers were alive they would make efforts to bring their daughters for follow up visits. In the case where fathers had died and brothers were married, they were reluctant to bring their sisters for treatment as their wives believed that this was the responsibility of the patients' husbands, not of their brothers. Accordingly, CKD as an outcome was also highest in the obstetrical category. Among the 280 women in this group developing CKD, 213 showed acute cortical necrosis (ACN) either on radiological findings, or histopathology, or both. Histopathology has shown both varieties, focal in some and diffuses patterns of $\mathrm{ACN}$ in others.

Acute gastroenteritis/diarrheal illness still remains on top of our medical causes of AKI though in recent years (group IV) malarial infections and toxic rhabdomyolysis mainly resulting from PPD poisoning has superseded this cause (Table-II). We have seen a change in trends of rhabdomyolysis during the last five years of this study. Previously this particular group used to include more crush syndrome and exercise induced rhabdomyolysis; now we see more of toxic rhabdomyolysis resulting from PPD ingestion. ${ }^{23}$ This is different from regional studies, where cases have been reported with multiple wasp stings, alcohol binge drinking, and a small number of cases from PPD poisoning and with dengue infection. ${ }^{17}$

Malaria; according to a 2018 WHO report, affects 228 million people worldwide, causing death to 405,000 people, mostly residing in the tropics / or mainly in LICs and LMICs. ${ }^{34}$ In malarial AKI we have seen that in the later period of the study, AKI caused by vivax malaria was increasing but predictors of mortality remain unchanged over the years. ${ }^{21,35}$ Another institution in the country has reported similar findings of increasing vivax malaria as cause of AKI. ${ }^{36}$ Overall reported contribution of malaria to AKI is 2-39\% in different populations. ${ }^{37}$ In comparison to tropical region smaller numbers are reported from western countries.

AKI resulting from dengue infection has also been reported in Pakistan where AKI was found in $13.3 \%(71 / 532)$ of all dengue cases studied. Approximately two-thirds (64.8\%) of these patients had mild AKI and a third (35.2\%) had moderate to severe $\mathrm{AKI}{ }^{38}$ In our study we have recorded dengue in patients who came with AKI (as this is tertiary care renal facility), so prevalence of AKI with dengue infection cannot be commented in this scenario. ${ }^{22}$

While snake bite causing AKI has been reported frequently from tropical countries over the last few decades some older studies discuss mechanisms of injury in detail. ${ }^{39}$ From our institution we have also published details of presentation and outcome in this particular group of medical AKI. ${ }^{25}$

Scorpion sting causing AKI has been reported less frequently, though health hazards associated with scorpion sting which is more common in Middle East, Iran, Latin America, South America, North Africa, India and Pakistan, has been reported. ${ }^{40}$ In a previous publication from our institution mechanisms of kidney injury has been discussed in some details. ${ }^{26}$

Surgical cause related to bilateral obstruction was included only in Group-I in this study, the reason being that with expansion of services and institutional premises, these cases were followed by urology counter members of our team. Keeping long term follow up for them became very difficult in a scenario where all data had been collected manually, requiring us to go through each and every case record or look at patients physically. In the majority of patients, the cause of obstruction was bilateral ureteric or renal stones or stone causing obstruction to the solitary functioning kidney. In some patients it was pelviureteric junction obstruction. There were a few cases of prostatic enlargement in males, cervical cancers in females or pelvic mass in both genders. (Table-IV).

Complete renal recovery in medical AKI over the years has shown small variation from group I to IV, similarly there was little decline in deaths during acute phase of illness over different groups. In obstetrical AKI number of women developing CKD is higher when compared to other groups. Different factors which revealed significance with mortality either in isolation or in combination are given in Table- $\mathrm{V}$. 


\section{CONCLUSION}

In this part of world, we still see AKI resulting from many preventable causes. This study addresses causes of CA-AKI from a LMIC for first time in such a large population. It also reflects that even when patients arriving with advanced renal dysfunction reaching to a facility where proper renal care can be provided it may give acceptable outcome in terms of patient survival and to variable extent renal survival as well. Provision of health care facility at door step might resolve issues of outcome of many partially recovered group of patients.

Acknowledgement: Valuable help of Mr. Iqbal Mujtaba (Research Dept. SIUT) for statistical analysis of data and Ms. Anika Khan (faculty at CBEC, SIUT) for grammatical corrections in manuscript is gratefully acknowledged.

Conflict of Interest: None.

Funding: None.

\section{REFERENCES}

1. Acute Kidney Injury. AKI 0by25.https://www.theisn.org/focus/ acute-kidney-injury. accessed on 20th July'2020 at $1050 \mathrm{hrs}$

2. KDIGO: Definition and classification of AKI. KI Suppl. 2012;2:19-36

3. Xue JL, Daniels F, Star RA, Kimmel PL, Eggers PW, Molitoris BA, Himmelfarb J, Collins AJ. Incidence and Mortality of Acute Renal Failure in Medicare Beneficiaries, 1992 to 2001. JASN. 2006;17:1135-1142.

4. Liano F, Pascual J, The Madrid Acute Renal Failure Group. Epidemiology of acute renal failure: A prospective, multicenter community- based study. KI. 1996;50:811-888.

5. https://www.nationsonline.org/oneworld/human development_low.htm accessed 21 July 2020 at 1325 hrs.

6. Hasan A, Mahmood K, Bukhsh HA. Healthcare System of Pakistan. Int J of Adv Res Publicat. 2017;1(4):170-174

7. https://tradingeconomics.com/pakistan/rural-populationpercent-of-total-population-wb-data.html accessed 29.4.2020 at $1520 \mathrm{hrs}$

8. Srisawat N, and SEA- AKI study group. The epidemiology and characteristics of acute kidney injury in the Southeast Asia intensive care unit: a prospective multicenter study. Nephrol Dial Trans. 2019:1-10

9. Agrawal RK, Hada R, Khakurel S, Baral A. Analysis of Eight Years Data of Renal Disorders in a Tertiary Care Hospital in Nepal. Postgrad Med J of NAMS. 2009;9(2):28-34.

10. Mostafi M, Nessa A, Fakir MAH, Bhuyian MAQ, Rahman M. Presentation and outcome of acute kidney injury in a tertiary military hospital of Bangladesh. Bangladesh J Med. 2011;22:35-40.

11. Hussain SW, Qadeer A, Munawar K, Qureshi MSS, Khan MT, Abdullah A, et al. Determining the incidence of AKI using the RIFLE Criteria in the medical ICU in a Tertiary Care Hospital Setting in Pakistan. Cureus. 2019;11(2):e4071. doi: 10.7759/Cureus.4071

12. Ali A, Zaffar S, Mehmood A, Nisar A. Obstetrical acute renal failure from Frontier Province: 3 years prospective study. JPMI. 2002;1891:109-116.

13. Naqvi R, Ahmed E, Akhtar F, Yazdani I, Zafar N, Naqvi A, et al. Analysis of Factors Causing Acute Renal Failure. J Pak Med Assoc. 1996;46(2):29-30.

14. Jha V, Malhotra HS, Sakhuja V, Chugh KS. Spectrum of hospitalacquired acute renal failure in the developing countries-Chandigarh study. Q J Med. 1992;83(303):497-505.
15. Prakash J, Tripathi K, Malhotra V, Kumar O, Srivastava PK. Acute renal failure in Eastern India. Nephrol Dial Trans. 1995;10:2009 2012.

16. Lameire N, Biesen WV, Vanholder R. The changing epidemiology of acte renal failure. Nat Clin Prac Nephrol. 2006;2(7):364-377.

17. Dhanapriya J, Dineshkumar T, Sakhtirajan R, Gopalakrishnan N. Acute Kidney Injury in Tropical Countries. EMJ Nephrol. 2017;5(1):66-74.

18. Lombardi R, Yu L, Younis-Ibrahim M, Schor N, Burdmann EA Epidemiology of Acute Kidney Injury in Latin America. Semin in Nephro. 2008;28(4):320-329.

19. Naicker S, Aboud O, Gharbi MB. Epidemiology of Acute Kidney Injury in Africa. Semin in Nephrol. 2008;28(4):348-353.

20. Rashid HU, Hossain RM, Khanam A. Outcome of acute renal failure in adults in a teaching hospital in Bangladesh. Ren Fail. 1993;15(5):603-607.

21. Naqvi R, Akhtar F, Ahmed E, Sheikh R, Bhatti S, Haider A, et al Malarial Acute Kidney Injury: 25 Years Experience from a Center in an Endemic Region. Brit J Med Med Res. 2016;12(6):1-6. Article no.BJMMR.21471.

22. Naqvi R. Dengue Infection Causing Acute Kidney Injury. Trop Med Surg. 2016;4:2 . doi: 10.4172/2329-9088.1000211

23. Naqvi R, Akhtar F, Ahmed E, Naqvi A, Rizvi A. Acute Kidney Injury with Rhabdomyolysis: 25 Years Experience from a Tertiary Care Center. Open J Nephrol. 2015;5:67-74. doi: 10.4236/ ojneph.2015.53011

24. Naqvi R, Ahmed E, Sheikh R, Rizvi A. Obstetrical Acute Kidney Injury: 25 Years' Experience from Nephrology Care Unit in Pakistan. Open Acc Lib J. 2015;2:e1778. doi: 10.4236/oalib.1101778

25. Naqvi R. Snake-bite-induced Acute Kidney Injury. J Coll Physicians Surg Pak. 2016;26(6):517-520.

26. Naqvi R. Scorpion Sting and Acute Kidney Injury: Case Series from Pakistan. Brit J Med Res. 2015; 9(10):1-6. Article no.BJMMR.19611.

27. Jha V, Prameswaran S. Community -acquired acute kidney injury in tropical countries. Nat Review Nephrol. 2013;9:278-290.

28. Sohail ML, Khan MS, Ijaz M, Naseer O, Fatima Z, Ahmad AS, et al. Seroprevalence and risk factor analysis of human leptospirosis in distinct climatic regions of Pakistan. Acta Tropica. 2018. doi: 10.1016/j.actatropica.2018.01.021

29. Prakash J, Pant P, Prakash S, Sivasankar M, Vohra R, Doley PK, et al. Changing picture of acute kidney injury in pregnancy: Study of 259 cases over a period of 33 years. Ind J Nephrol. 2016;26(4):262267.

30. Lim SS, Dandona L, Hoisington JA, James SL, Hogan MC, Gakidou E. India's Janani Suraksha Yojana, a conditional cash transfer programme to increase births in health facilities: an impact evaluation. Lancet. 2010;375:2009-2.

31. Karumanchi SA, Maynard SE, Stillman IE, Epstein FH, Sukhatme VP. Preeclampsia: A renal perspective. Kid Int. 2005;67:2101-2113.

32. Kessous R, Shoham-Vardi I, Pariente G, Sergienko R, Sheiner E. An association between intrauterine fetal death and long term maternal renal complications. S280-1 Am J of Obstet Gynecol. 2014; S280-1 (Abst).

33. Huerta A, Arjona E, Portoles J, Lopez-Sanchez P, Rabasco C, Espinosa M, et al. A retrospective study of pregnancy- associated atypical hemolytic uremic syndrome. Kidney Int. 2018;93(2):450459.

34. www.who.int accessed on 27 April 2020 at 14.24 hours.

35. Naqvi R, Ahmed E, Akhtar F, Naqvi A, Rizvi A. Outcome in Severe Acute Renal Failure Associated with Malaria. Nephrol. Dial. Trans. 2003;18(9):1820-1823.

36. Imtiaz S, Drohlia MF, Nasir K, Hussain M, Ahmed A. Morbidity and mortality with Plasmodium vivax and Plasmodium falciparum infection in a tertiary care kidney hospital. Saudi J Kid Dis Transp. 2015;26:1169-1176.

37. Mishra SK, Das BS. Malaria and acute kidney injury. Semin in Nephrol. 2008;28(4):395-408.

38. Khalil MAM, Sarwar S, Chaudry MA, Maqbool B, Khalil Z, Tan J, et al. Acute kidney injury in dengue virus infection. Clin Kidney J. 2012;5:390-394.

39. Chugh KS. Snake bite induced acute renal failure in India.KI 1989;35:891-907.

40. Isbister GK, Bawaskar HS. Scorpion Envenomation. NEJM. 2014;371:457-463 